\title{
Damage Model of Reinforced Concrete Members under Cyclic Loading
}

\author{
Bo Chen Wei ${ }^{1,2}$, Jing Shu Zhang ${ }^{1,2, ~ *}$, Yin Hua Zhang ${ }^{3}$, and Jia Lai Zhou ${ }^{1,2}$ \\ ${ }^{1}$ Key Laboratory of Mechanics on Disaster and Environment in Western China of the Ministry of Education, Lanzhou University, \\ Lanzhou 730000, China \\ ${ }^{2}$ School of Civil Engineering and Mechanics, Lanzhou University, Lanzhou 730000, China \\ ${ }^{3}$ Gansu Institute of Architectural Design and Research, Lanzhou 730000, China
}

\begin{abstract}
Based on the Kumar damage model, a new damage model for reinforced concrete members is established in this paper. According to the damage characteristics of reinforced concrete members subjected to cyclic loading, four judgment conditions for determining the rationality of damage models are put forward. An ideal damage index (D) is supposed to vary within a scale of zero (no damage) to one (collapse). D should be a monotone increasing function which tends to increase in the case of the same displacement amplitude. As for members under large displacement amplitude loading, the growth rate of D should be greater than that of D under small amplitude displacement loading. Subsequently, the Park-Ang damage model, the Niu-Ren damage model, the Lu-Wang damage model and the proposed damage model are analyzed for 30 experimental reinforced concrete members, including slabs, walls, beams and columns. The results show that current damage models do not fully matches the reasonable judgment conditions, but the proposed damage model does. Therefore, a conclusion can be drawn that the proposed damage model can be used for evaluating and predicting damage performance of RC members under cyclic loading.
\end{abstract}

\section{Introduction}

The failure of structure subjected to earthquake action is essentially caused by the accumulation of irreversible damage. Seismic performance of structure is the damage performance during earthquakes in essence [1]. Among various evaluation methods for seismic performance, the damage index $\mathrm{D}$ involved in damage models is more rational for evaluating damage state of structures and members. In addition, a damage model is established on the basis of performance-based seismic design and seismic damage assessment.

There mainly exist current failure criteria such as strength-based failure criteria, deformation-based failure criteria, energy-based failure criteria, deformation and energy-based failure criteria, and performance-based failure criteria [2]. Based on different failure criteria and experimental researches as well as seismic damage investigations, a variety of damage models are proposed. However, the damage index $\mathrm{D}$, which ranges from 0 to 1 as per the definition, has to be determined for whatever damage model. D is a value of 0 in the absence of damage and a value of 1 in the case of complete failure. The larger the value $\mathrm{D}$ is, the more serious damage extent will become.

The damage state of RC members has not been described accurately by current damage models due to the complexity of damage development. There exist common problems that damage index $\mathrm{D}$ is larger than 0 when members are in elastic range, and the $\mathrm{D}$ is not converged to 1 when they approach to collapse.

In order to investigate above several key aspects, taking into consideration characteristics of current damage models at home and abroad, a damage model that is capable of a real reflection of RC members under cyclic loading is proposed on the basis of slabs, walls, beams and columns, $30 \mathrm{RC}$ members in total.

\section{Current main damage models}

Damage models can be divided into two types: noncumulative damage models and cumulative damage models. Taking into account the effect of first excursion, the former is simpler generally and mostly based on displacement [3], stiffness [4,5] and so forth. Loading histories and loading paths can not be characterized by the models, which suggest that they are not suitable for RC members subjected to cyclic loading.

Main cumulative damage models are listed in Table 1, most of which belong to double variables damage models based on dual deformation-energy failure criteria, and take into consideration the interactive effects on failure boundaries of maximum responses (e.g. strength, displacement or ductility) and cumulative damages (e.g. cracks, energy dissipation). These damage models are more suitable for RC members under cyclic loading.

\footnotetext{
* Corresponding author: jshzhang@1zu.edu.cn
} 
Table 1. Cumulative damage models.

\begin{tabular}{|c|c|c|}
\hline Scholars & Damage models & Characteristics \\
\hline $\begin{array}{l}\text { Park, Ang } \\
{[6]}\end{array}$ & $D=\frac{X_{\mathrm{m}}}{X_{\text {u,mon }}}+\beta \frac{E_{\mathrm{h}}}{F_{\mathrm{y}} X_{\text {u,mon }}}$ & $\begin{array}{l}\text { A Simple form, and having } \\
\text { wide } \\
\text { foundation }\end{array}$ \\
\hline $\begin{array}{l}\text { Ou J P, } \\
\text { Niu D T } \\
{[7]}\end{array}$ & $D=\left(\frac{X_{\mathrm{m}}}{X_{\mathrm{u}}}\right)^{\beta}+\left(\frac{E_{\mathrm{h}}}{E_{\mathrm{u}}}\right)^{\beta}$ & $\begin{array}{l}\text { Same weights of energy } \\
\text { dissipation component and } \\
\text { displacement component }\end{array}$ \\
\hline Fajfar [8] & $D=\frac{E_{\mathrm{h}}}{F_{\mathrm{y}}\left(X_{\mathrm{u}, \text { mon }}-X_{\mathrm{y}}\right)}$ & $\begin{array}{l}\text { One variable form, enabling } \\
\text { to take into account the } \\
\text { effects of low-cycle fatigue }\end{array}$ \\
\hline $\begin{array}{l}\text { Kumar, et } \\
\text { al [9] }\end{array}$ & $\begin{array}{l}D=(1-\beta)\left(\frac{X_{\mathrm{m}}-X_{\mathrm{y}}}{X_{\mathrm{u}, \mathrm{mon}}-X_{\mathrm{y}}}\right. \\
+\beta\left(\frac{E_{i}}{F_{\mathrm{y}}\left(X_{\mathrm{u}, \mathrm{mon}}-X_{\mathrm{y}}\right)}\right)^{c}\end{array}$ & $\begin{array}{l}\text { Regarding the damage } \\
\text { caused by displacement and } \\
\text { energy dissipation as } \\
\text { nonlinearity }\end{array}$ \\
\hline $\begin{array}{l}\text { Niu D T, } \\
\text { Ren L J } \\
{[10]}\end{array}$ & $D=\frac{X_{\mathrm{m}}}{X_{\mathrm{u}}}+\alpha\left(\frac{E_{\mathrm{h}}}{E_{\mathrm{u}}}\right)^{\beta}$ & $\begin{array}{l}\text { Various combinations with } \\
\text { displacement and energy } \\
\text { dissipation components, good } \\
\text { upper convergence ability }\end{array}$ \\
\hline $\begin{array}{l}\text { Lu D G, } \\
\text { Wang G } \\
\text { Y [11] }\end{array}$ & $\begin{array}{l}D=(1-\beta) \frac{X_{\mathrm{m}}-X_{\mathrm{y}}}{X_{\mathrm{u}}-X_{\mathrm{y}}} \\
+\beta \frac{E_{\mathrm{h}}}{F_{\mathrm{y}}\left(X_{\mathrm{u}}-X_{\mathrm{y}}\right)}\end{array}$ & $\begin{array}{l}\text { Convenient calculation and } \\
\text { performance design for } \\
\text { seismic damage }\end{array}$ \\
\hline
\end{tabular}

Where $X_{\mathrm{m}}, X_{\mathrm{y}}$ denote the maximum displacement and yielding displacement through whole loading process, respectively. $X_{\mathrm{u}, \mathrm{mon}}$ is the ultimate displacement of the structure subjected to monotonic loading. $X_{\mathrm{u}}$ is the ultimate deformation. $E_{\mathrm{h}}$ is the cumulative dissipated hysteresis energy. $E_{\mathrm{u}}$ is the ultimate dissipated hysteresis energy. $E_{i}$ denotes the dissipated energy of $i$ th half circle. $c, \alpha$ and $\beta$ are constants involved in those models.

\section{The proposed damage model}

Kumar and Usami [9] studied the mechanical properties of steel members under cyclic loading and put forward a suitable damage model, where displacement component and energy dissipation component were regarded as nonlinearity, and these two components were a combination of the model parameter $\beta$. It covered a wide range of applications and was capable of taking into account damage exacerbation due to large displacement. Aimed at making it suited for RC members, the damage model is modified appropriately.

\subsection{Parameters involved in Kumar damage model}

The Kumar damage model seemed to be derived from equation 1 and 2. By employing experimental data of Usami[12], Kumar et al assumed damage index was equal to 1 when members were in the ultimate state to calculate the exponential item $c$ by means of trail-anderror method, and the results are given in Table 2. With the purpose that large displacement circle occupied larger weight, Kumar suggested the value c should be equal to 2 . Then, the parameter $\beta$ was obtained by trailand-error method.

$$
\begin{gathered}
D=\sum_{i=1}^{N}\left(\frac{X_{\mathrm{m}}-X_{\mathrm{y}}}{X_{\mathrm{u}, \mathrm{mon}}-X_{\mathrm{y}}}\right)^{c} \\
D=\sum_{i=1}^{N}\left(\frac{E_{i}}{E_{\mathrm{mon}}}\right)^{c}
\end{gathered}
$$

Table 2. The parameters involved in Kumar damage model.

\begin{tabular}{lccc}
\hline & $\begin{array}{c}\text { Usami's [12] } \\
\text { steel columns }\end{array}$ & Experiment of \\
\cline { 2 - 4 } & $\begin{array}{c}c \\
\text { (Eqn. 1) }\end{array}$ & $\begin{array}{c}c \\
\text { (Eqn. 2) }\end{array}$ & $\beta$ \\
\hline $\begin{array}{l}\text { Loading three times } \\
\text { with same amplitude of } \\
\text { displacement per cycle }\end{array}$ & 2.9 & 3.7 & 0.11 \\
$\begin{array}{l}\text { Loading with constant } \\
\text { amplitude }\end{array}$ & 3.0 & 3.1 & 0.12 \\
Mean values & 2.9 & 3.5 & 0.11 \\
\hline
\end{tabular}

The Kunnath's experimental data of reinforced concrete bridge piers was used for figuring out the model parameters. The results are given in Table 3. Calculation results indicated that the Kumar damage model maintained better parametric stability when applied to $\mathrm{RC}$ members. Compared with steel members in Table 2, the value of the parameter $c$ of RC members was smaller, while the parameter $\beta$ was approximately equal to 0.3 .

Table 3. The parameters involved in Kumar damage model for RC members.

\begin{tabular}{lccc}
\hline & \multicolumn{3}{c}{$\begin{array}{l}\text { Kunnath's [13] Experiment of } \\
\text { RC members }\end{array}$} \\
\cline { 2 - 4 } & $\begin{array}{c}c \\
\text { (Eqn. 1) }\end{array}$ & $\begin{array}{c}c \\
\text { (Eqn. 2) }\end{array}$ & $\beta$ \\
\hline $\begin{array}{l}\text { Loading three times } \\
\text { with same amplitude } \\
\text { of displacement per } \\
\text { cycle }\end{array}$ & 2.8 & 3.0 & 0.29 \\
$\begin{array}{l}\text { Loading with constant } \\
\text { amplitude }\end{array}$ & 2.9 & 3.0 & 0.27 \\
Mean values & 2.9 & 3.0 & 0.28 \\
\hline
\end{tabular}

On the basis of parameters involved in the model calibrated by Kunnath's [13] experimental data, the calculative results of the experimental specimen A2 under changeable amplitude loading conditions are given in Figure 1, from which it can be seen that the growth of damage index has no significant changes, nevertheless, maximum loads lead to the obvious growth of damage index. It is also observed that damage aggravation causes the decrease of bearing capacity. Kumar [9] has once observed the phenomenon in Usami's experiment.

A key aspect from above calculative results is, differing from steel members, that concrete is a kind of heterogeneous material within which there exist 
inevitable flaws such as pores, cracks between porosity and interface. RC structures are not ideal elastic-plastic body. A small amount of cumulative plastic damage of $\mathrm{RC}$ members is caused prior to yielding. However, the results calculated by the Kumar damage model do not reflect that phenomenon.

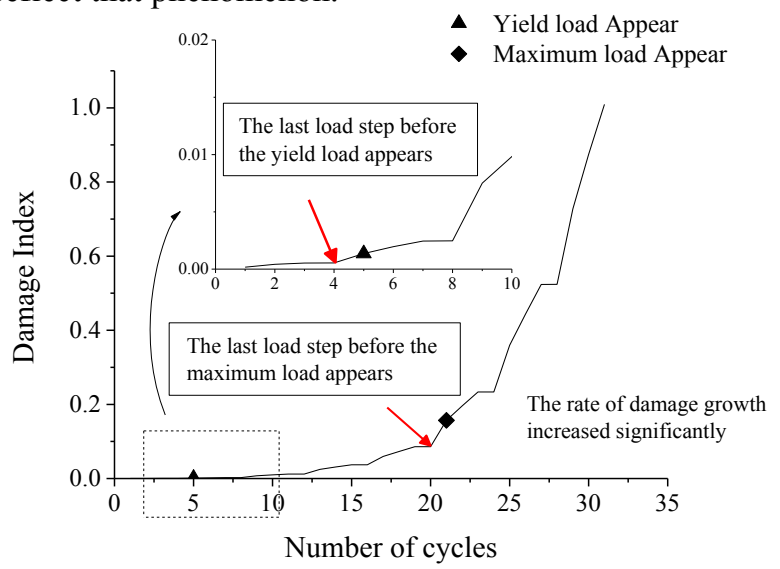

Fig. 1. Damage index of specimen A2.

\subsection{The proposed damage model}

For the members having similar mechanical properties when subjected to positive and reverse loading, dissipated energy of $i$ th half circle $E_{i}$ is transformed into that of a circle to simplify Kumar damage model. At the same time, dissipated energy $E_{\text {mon }}$ multiplies by two when members are under monotonic loading. The parameters involved in the model are figured out by trail-and-error method based on Kunnath's empirical data. The results are given in Table 4.

Table 4. The Parameters involved in simplified Kumar damage model for RC structures.

\begin{tabular}{lccc}
\hline Loading methods & $\begin{array}{c}c \\
\text { (Eqn. 1) }\end{array}$ & $\begin{array}{c}c \\
\text { (Eqn. 2) }\end{array}$ & $\beta$ \\
\hline $\begin{array}{l}\text { Loading three times } \\
\text { with same amplitude of } \\
\text { displacement per cycle }\end{array}$ & 2.1 & 2.3 & 0.61 \\
$\begin{array}{l}\text { Loading with constant } \\
\text { amplitude }\end{array}$ & 2.4 & 2.4 & 0.54 \\
Mean values & 2.3 & 2.4 & 0.58 \\
\hline
\end{tabular}

In order to enhance convergence ability of Kumar damage model, dissipated energy component is rewritten and displacement component $X_{\mathrm{y}}$ is omitted at the same time. Then, the damage index of the proposed model can be written by the form:

$$
D=(1-\beta)\left(\frac{X_{\mathrm{m}}}{X_{\mathrm{u}}}\right)^{c_{1}}+\beta\left(\frac{E_{\mathrm{h}}}{E_{\mathrm{u}}}\right)^{c_{2}}
$$

Where, $\beta$ a combination parameter evaluating the importance of displacement component and energy component, can be taken as 0.6 from Table 4 to keep the proportion of two components constant when members are at failure. Both of $c_{1}$ and $c_{2}$ are the exponential items' parameters. $c_{2}$ can be taken as 2.0 , so as to give more importance to the larger plastic deformation, as Kumar suggested [9].

When at yielding, members are considered to approach to the upper limit of good condition. As the code [14] suggests, $\mathrm{D}=0.1$ is an appropriate value for members at yielding. Hence, the exponential items' parameter $c_{2}$, the last unknown parameter, can be figured out by means of trail-and-error method. By employing experimental data of Zhang [15], the value of $c_{2}$ can be calculated as 1.2.

In this model, cumulative dissipated hysteretic energy $E_{\mathrm{h}}$ is normalized by ultimate dissipated hysteretic energy $E_{\mathrm{u}}$ to improve the upper limit convergence ability of the model. By employing different parameters $c_{1}$ and $c_{2}$, the relationship between total damage and displacement component damage, as well as the relationship between total damage and dissipated energy component damage can be evaluated to improve applicability of the model for different kinds of members.

\section{Damage model rationality}

A variety of current damage models differ significantly, and it is of much necessity to judge whether the damage model are rational according to some conditions.

\subsection{Judging conditions for damage models rationality}

For RC members subjected to cyclic loading, damage model rationality can be judged based on the following conditions:

Condition 1: D should have upper and lower limit convergences. $\mathrm{D}$ is a value of 0 when no damage occurs and a value of 1 in the case of complete failure.

Condition 2: The damage of members is irreversible. $\mathrm{D}$ is supposed to be a monotone increasing function.

Condition 3: Damage models should exhibit the effects of low-cycle fatigue when members are under same displacement cyclic loading, which means that D should tend to increase in this condition.

Condition 4: Damage models should exhibit that large displacement amplitude loading has larger influence on members' damage, compared with small displacement amplitude loading [16]. The growth rate of $\mathrm{D}$ under large displacement amplitude loading, should be greater than that of $\mathrm{D}$ under loading conditions with small amplitude of displacement.

Both of conditions 1 and 2 belong to the qualifications for basic framework of the whole damage models, which can be stated that all of damage models should match conditions 1 and 2. Conditions 3 and 4 refer to requirements of damage models' performance, which aim at guaranteeing the rationality of damage models for assessing the damage state of members.

\subsection{Rationality judgments for damage models}

The analysis of classical Park-Ang damage model [6], Niu-Ren damage model [10], Lu-Wang damage model 
[11] and the proposed damage model, is based on the following parameter values:

(1) For the Park-Ang damage model, $X_{\mathrm{u} \text {,mon }}$ is taken as $X_{\mathrm{u}} / 0.62$ which is obtained by analyzing quantities of experiments in that paper [17]. The parameter $\beta$ is a value of 0.05 for well-confined RC members [18].

(2) For the Niu-Ren damage model, $\alpha=0.1387$ and $\beta=0.0814[10]$.

(3) For the Lu-Wang damage model, parameter $\beta$ is equal to 0.15 [19], and a value of 0 when the damage index is calculated to be negative.

(4) For the proposed damage model, parameters are involved in Section 3.

By employing experimental data of slabs [15], walls [20], beams [21,22] and columns [23], 30 RC members in total, damage state of members applied to various damage models are analyzed, as plotted in Figures 2 to 6 . The results of $\mathrm{D}$ calculated by different damage models when members are at yielding or in the ultimate state, are given in Table 5 .

Table 5. Damage indices involved in various RC members.

\begin{tabular}{cccccc}
\hline \multirow{2}{*}{$\begin{array}{c}\text { Damage } \\
\text { models }\end{array}$} & $\begin{array}{c}\text { Damage } \\
\text { index }\end{array}$ & $\begin{array}{c}\text { Mean } \\
\text { values }\end{array}$ & & $\begin{array}{c}\text { Damage } \\
\text { index }\end{array}$ & $\begin{array}{c}\text { Mean } \\
\text { values }\end{array}$ \\
\cline { 2 - 3 } \cline { 5 - 6 } Park-Ang & $0.102-0.417$ & 0.196 & & $0.690-1.066$ & 0.822 \\
Lu-Wang & $0.005-0.244$ & 0.094 & & $1.366-3.390$ & 2.152 \\
Niu-Ren & $0.253-0.747$ & 0.404 & & $1.138-1.139$ & 1.139 \\
Prop & $0.041-$ & 0. & $1.000-$ & 1. \\
\hline
\end{tabular}

On the basis of calculation results, considering the proposed rationality judgments for damage models, the rationalities of various damage models are analyzed as follows:

Condition 1: From Figures 2 to 6 and Table 5, combination forms and normalized forms of components in damage models have a significant impact on their convergence abilities. When members are in the ultimate state, the average value of damage index of the Park-Ang damage model is equal to 0.822 , slightly below a theoretical value of 1 . And the average value of damage index of the Lu-Wang damage model is equal to 2.152 , beyond a theoretical value of 1 . The damage index of the Niu-Ren damage model ranges from 1.138 to 1.139 , which is close to theoretical value of 1 . It is worth noting that the proposed damage model whose average value of $\mathrm{D}$ is equal to 1.005 , has better upper limit convergence ability owing to the normalized form of dissipated energy.

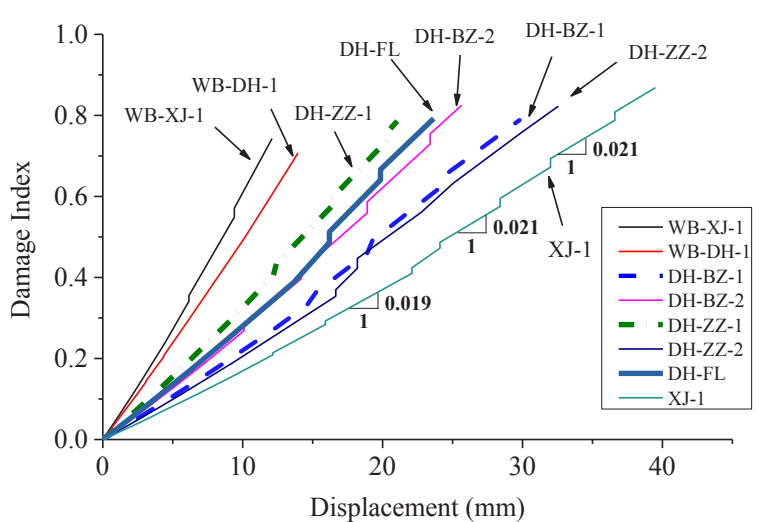

(a)

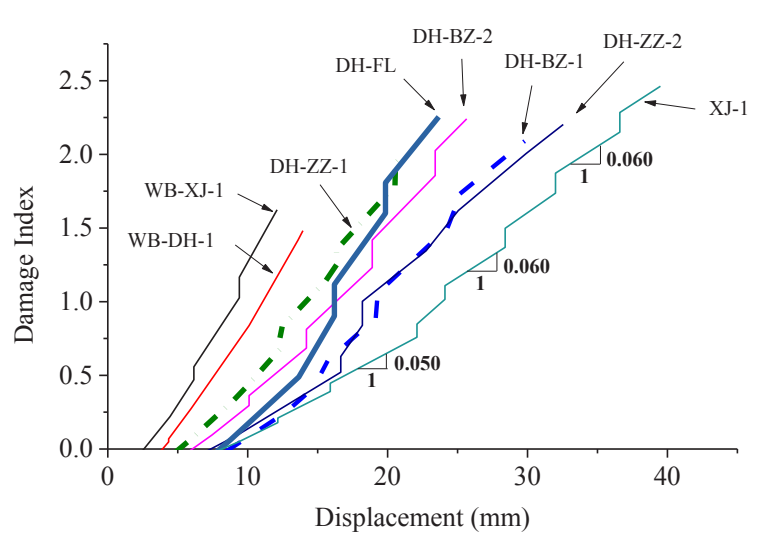

(b)

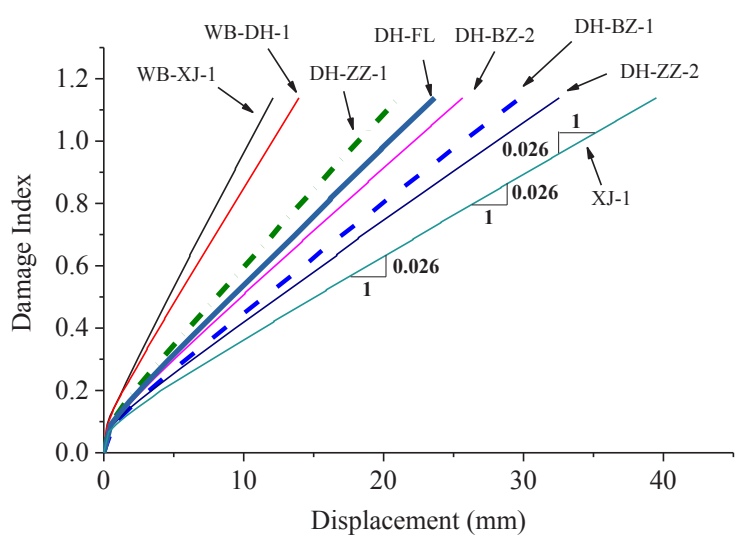

(c)

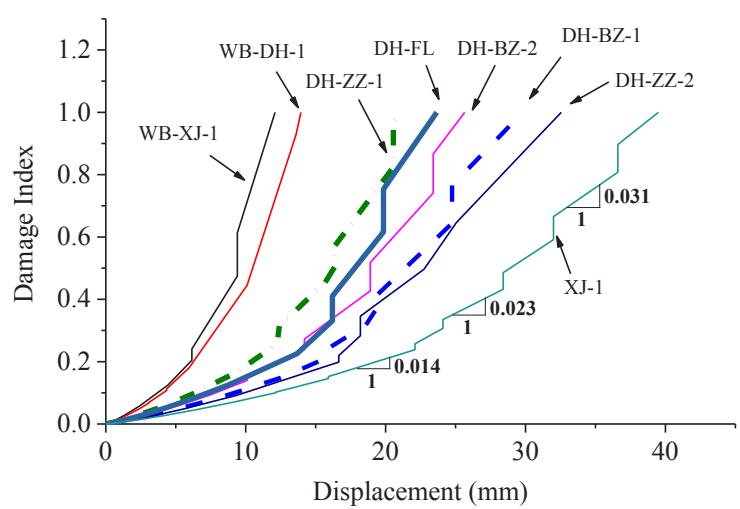

(d)

Fig. 2. Damage state of RC composite slabs with precast ribbed bottom panel. (a) Park-Ang damage model. (b) LuWang damage model. (c) Niu-Ren damage model. (d) The proposed damage model. 


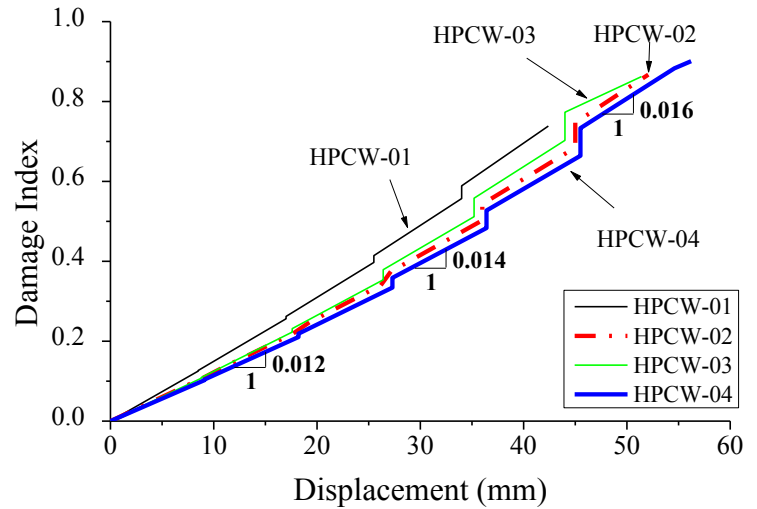

(a)

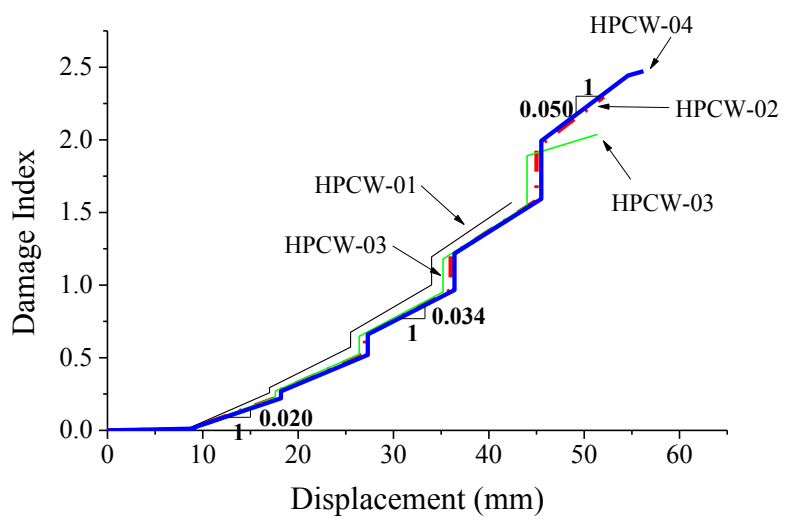

(b)

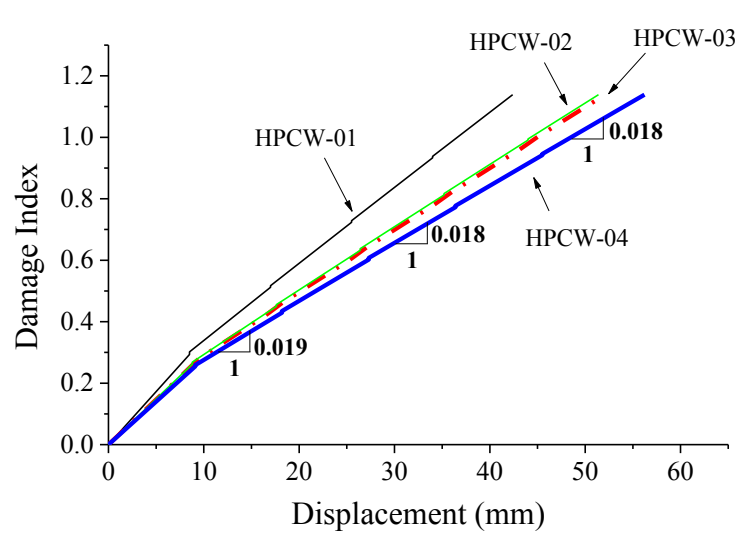

(c)

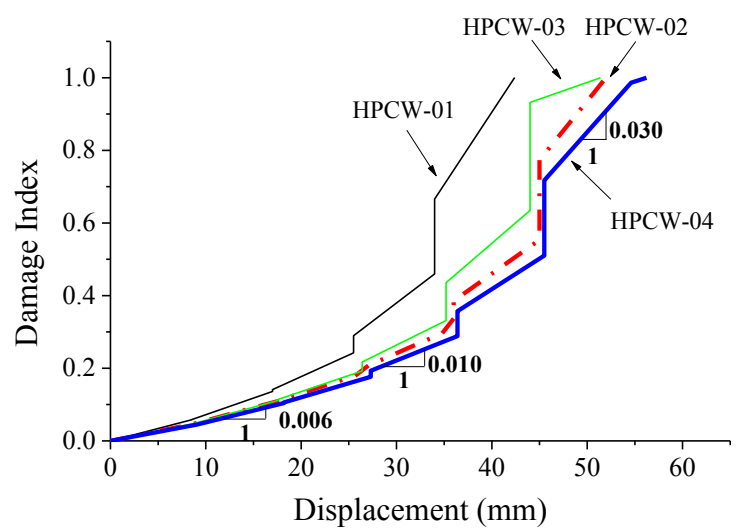

(d)

Fig. 3. Damage state of high-performance concrete shear walls. (a) Park-Ang damage model. (b) Lu-Wang damage model. (c) Niu-Ren damage model. (d) The proposed damage model.

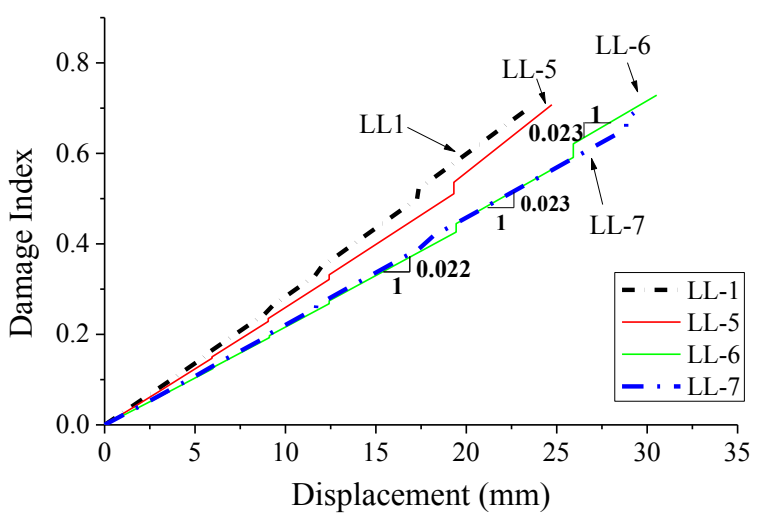

(a)

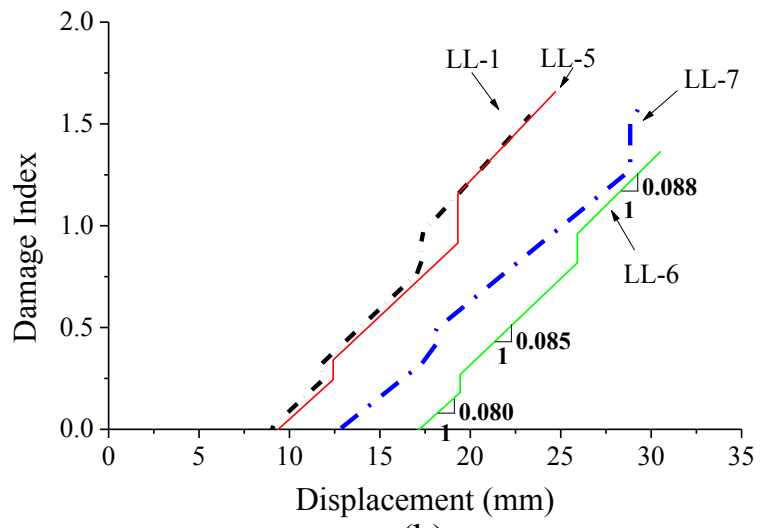

(b)

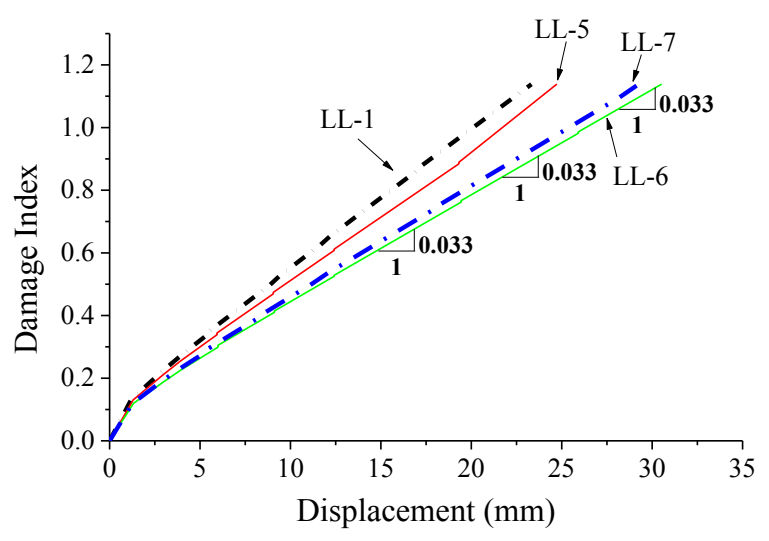

(c)

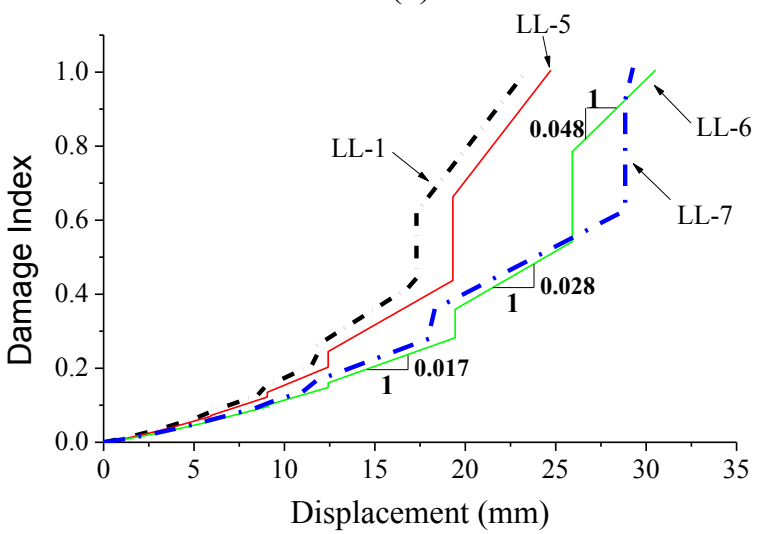

(d)

Fig. 4. Damage state of deep coupling beams with new reinforcement layouts. (a) Park-Ang damage model. (b) LuWang damage model. (c) Niu-Ren damage model. (d) The proposed damage model. 


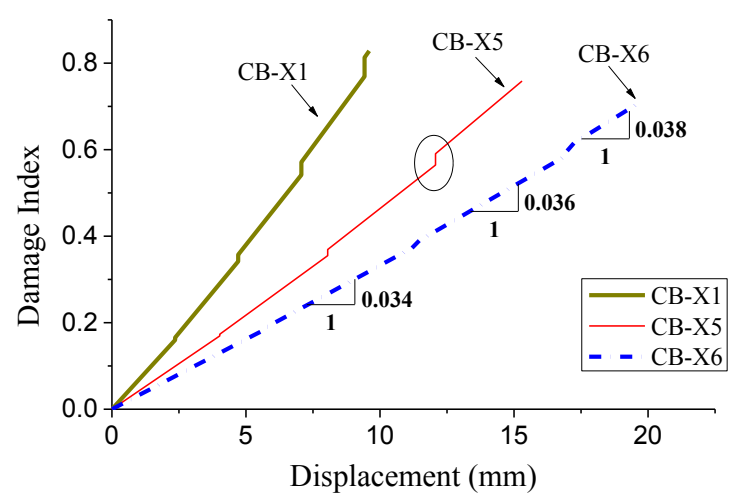

(a)

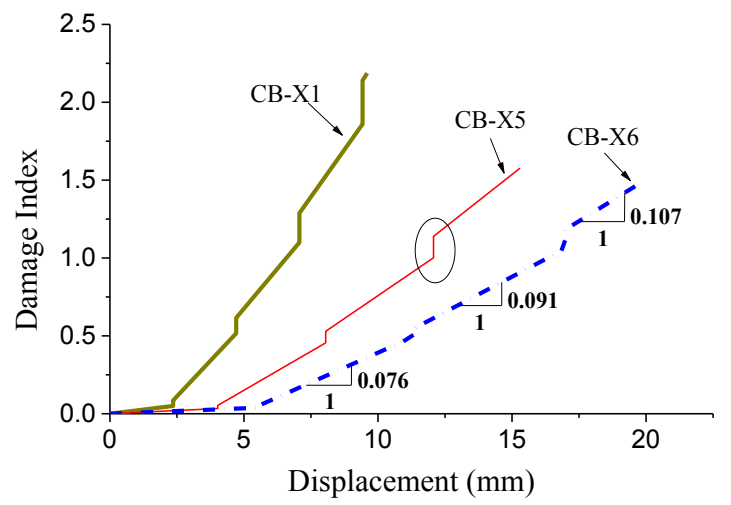

(b)

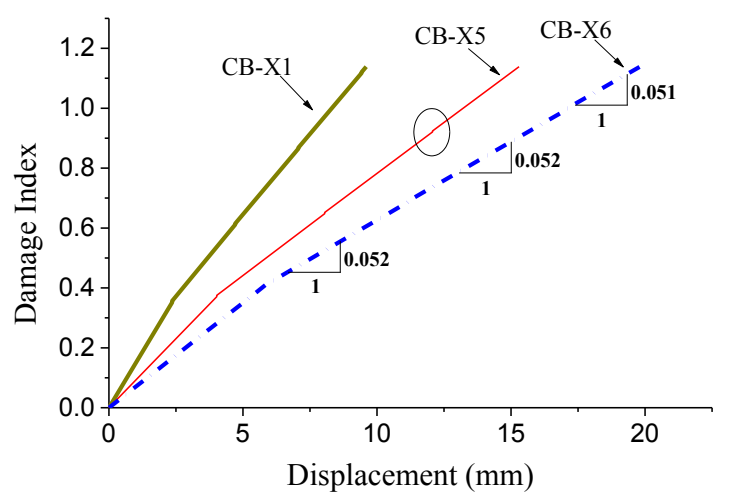

(c)

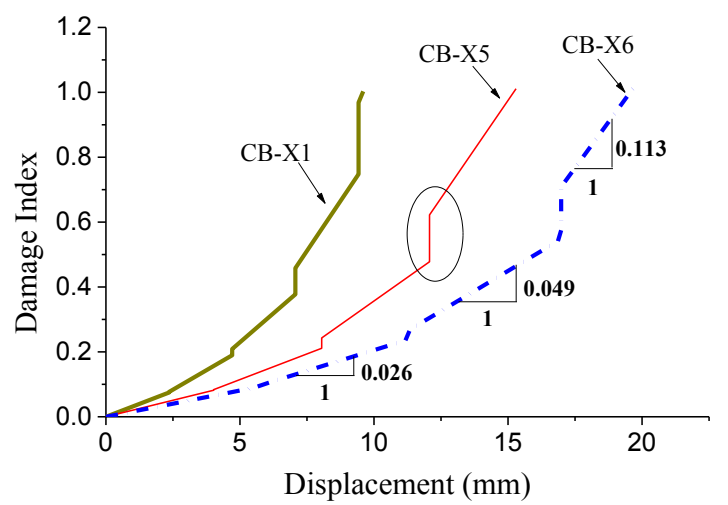

(d)

Fig. 5. Damage state of short-span coupling beams with bidiagonally reinforced bar. (a) Park-Ang damage model. (b) Lu-Wang damage model. (c) Niu-Ren damage model. (d) The proposed damage model.

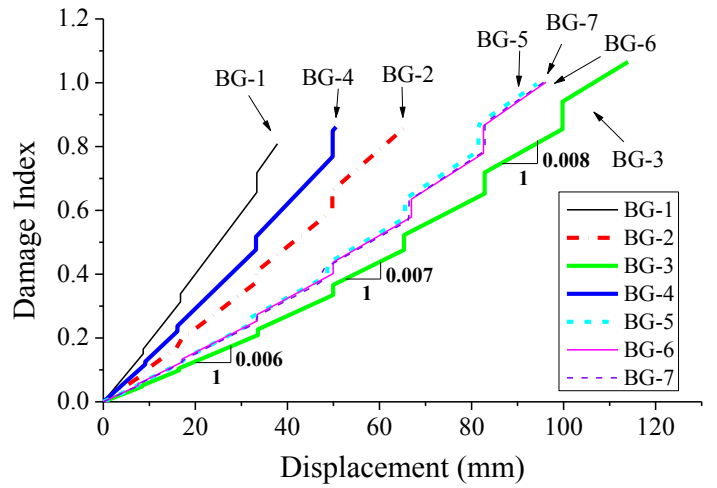

(a)

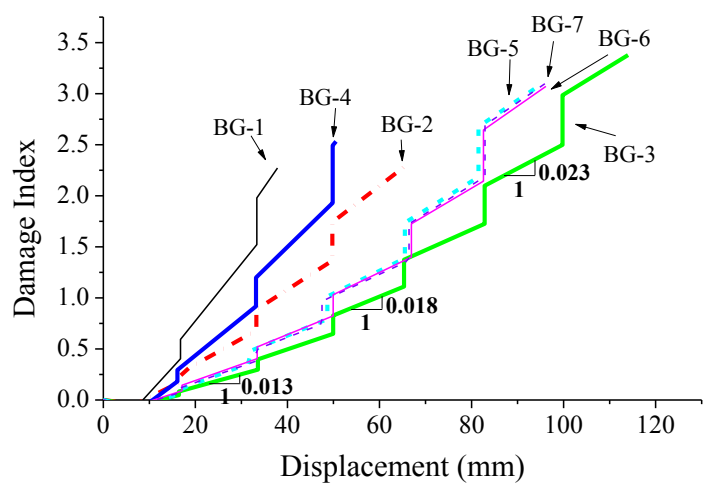

(b)

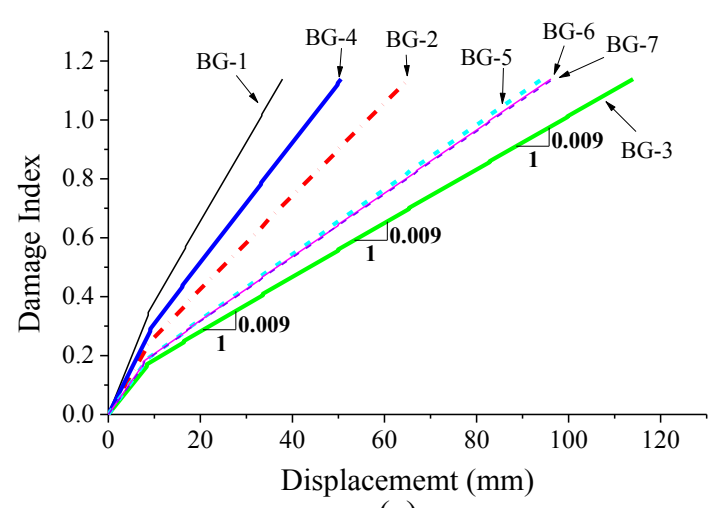

(c)

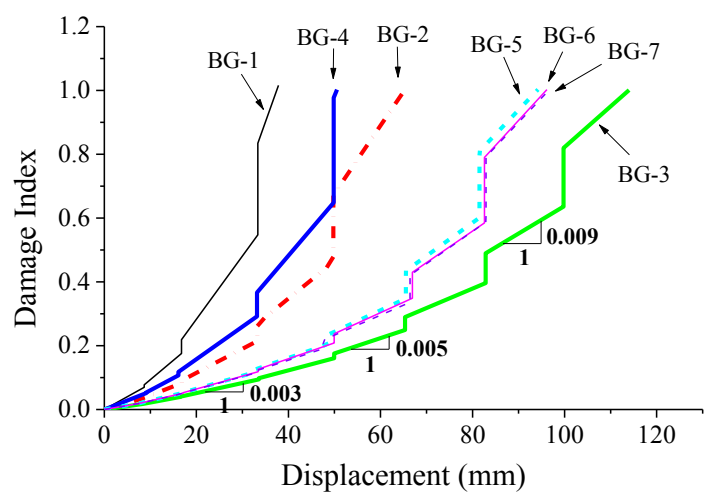

(d)

Fig. 6. Damage state of reinforced concrete columns with welded reinforcement grids. (a) Park-Ang damage model. (b) Lu-Wang damage model. (c) Niu-Ren damage model. (d) The proposed damage model. 
Condition 2: As shown in Figures 2 to 6, the damage index tends to increase. Namely, the whole damage models exhibit a monotone increasing.

Condition 3: From Figures 2 to 6, it is not observed for Niu-Ren damage model that there emerges obvious low-cycle fatigue phenomenon called "damage index jump". The reason is that dissipated energy component makes little effect on the whole, which means the exponential item $\beta$ is an absolutely small value. However, the phenomenon can be observed significantly for the others. Except for Niu-Ren damage model, the "damage index jumps" of other models under the same displacement is illustrated by the circles in Figure 5.

Condition 4: The slopes of displacement-damage index curves are partially labeled in Figures 2 to 6 , in which the Park-Ang and Lu-Wang damage models exhibit fainter growth of the slopes, and the Niu-Ren damage model don't exhibit any growth of slope. The three above models estimate the damage state of members as a linear trend in the mass, which does not indicate an increasing rate of members' damage development under large displacement loading. Nonetheless, the proposed damage model exhibits significant nonlinear characters.

The adaptabilities of judging conditions for various models are collected in Table 6 . On account of the complexity of damage development in RC members, most of current damage models incompletely satisfy above judging conditions. However, the proposed damage model is capable of meeting the conditions all above. Thus, it can be used for description the damage development of RC members.

Table 6. The definitions of rationality for various damage models based on judging conditions.

\begin{tabular}{lcccc}
\hline \multirow{2}{*}{$\begin{array}{l}\text { Damage } \\
\text { models }\end{array}$} & \multicolumn{4}{c}{ Judging condition } \\
\cline { 2 - 5 } & 1 & 2 & 3 & 4 \\
\hline Park-Ang & $\bigcirc$ & $\bullet$ & $\bullet$ & $\bigcirc$ \\
Lu-Wang & $\bigcirc$ & $\bullet$ & $\bullet$ & $\bigcirc$ \\
Niu-Ren & $\bullet$ & $\bullet$ & $\bigcirc$ & $\bigcirc$ \\
Proposed & $\bullet$ & $\bullet$ & $\bullet$ & $\bullet$ \\
\hline
\end{tabular}

Where fully satisfying the judging conditions is denoted by $\bullet$. Incompletely satisfying the conditions is denote by $\circ$. Not satisfying the conditions is denoted by o.

\section{Conclusions}

In this paper, the analysis of the Park-Ang damage model, the Niu-Ren damage model, the Lu-Wang damage model and the proposed damage model by employing the experimental data of slabs, walls, beams and columns, $30 \mathrm{RC}$ members in total, allows the following conclusions to be drawn:

(1) Four judging conditions for rationality of damage models are put forward: Damage index $\mathrm{D}$ is a value of 0 in the absence of damage and a value of 1 in the case of complete failure; $\mathrm{D}$ is supposed to be a monotone increasing function; D should tend to increase under the same displacement cycles; and the growth rate of $\mathrm{D}$ under large amplitude of displacement loading should be greater than that of D under small amplitude of displacement loading.

(2) Most of current damage models incompletely satisfy rationality judging conditions. However, the proposed damage model based on Kumar damage model, which matches the rationality judging conditions, can be used for evaluating and predicting damage performance of RC members under cyclic loading.

\section{Acknowledgements}

This work was supported by the National Natural Science Foundation of China [grant number 51078176, 51678283]. The Kunnath and Saatcioglu empirical data used in this paper are from the PEER Structural Performance Database. The authors are grateful for that.

\section{References}

1. G. Y. Wang, Practical Methods of Optimum Aseismic Design for Engineering Structures and Systems (China Achitecture\&Building Press, Beijing, 1999)

2. G. H. Li, X. Zhu, Earthq Eng. Eng. Vibrat. 26 67-69 (2006)

3. E. Cosenza, G. Manfredi, R. Ramasco, Earthquake Eng. Struct. Dyn. 22 855-868 (1993)

4. A. Ghobarah, H. Abouelfath, A. Biddah, Earthquake Eng. Struct. Dyn. 28 79-104 (1999)

5. T. H. Kim, K. M. Lee, Y. S. Chung, H. M. Shin, Eng. Struct. 27 576-592 (2005)

6. Y. J. Park and H. S. Ang, J. Struct. Eng. $111722-$ 739 (1985)

7. J. P. Ou, D. T. Niu, G. Y. Wang, Earthq Eng. Eng. Vibrat. 10 9-20 (1990)

8. P. Fajfar, Earthquake Eng. Struct. Dyn. 21 837-848 (1992)

9. S. Kumar, T.Usami, J. Struct. Engng. 40 177-188 (1994)

10. D. T. Niu, L. J. Ren, Earthq Eng. Eng. Vibrat. 16 44-54 (1996)

11. D. G. Lu, G. Y. Wang, Chin. Civi.l Eng. J. 34 44-49 (2001)

12. T. Usami, S. Banno, H. Zetsu, T. Aoki, Jpn. J. Struct. Eng. 39A 235-247 (1993)

13. S. K. Kunnath, A. El-Bahy, A. Taylor, W. C. Stone, Cumulative seismic damage of reinforced concrete bridge piers (NIST Interagency/Internal Report, Buffalo, 1997)

14. J. J. Sun, Y. F. Hong, Z. P. Wen, The chinese seismic intensity scale (Standards Press of China, Beijing, 2008) 
15. J. S. Zhang, Research on seismic performance of concrete composite slabs with precast ribbed bottom panels (Lanzhou University, Lanzhou, 2013)

16. J. P. Fu, M. Wang, S. L. Bai, Earthq Eng. Eng. Vibrat. 25 44-54 (1996)

17. CEB-FIP, Displacement based seismic design of reinforced concrete buildings (CEB-FIP, Lausanne, 2003)

18. CEB, Seismic design of reinforced concrete structures for controlled inelastic response (CEB, Lausanne, 1998)

19. Y. H. Zhang, Damage Index Evaluation Method for Seismic Performance of Structural Members (Lanzhou University, Lanzhou, 2013)

20. X. W. Liang, M. K. Deng, X. H. Zhang, S. F. Tian, J. Build. Struc. 28 80-88 (2007)

21. C. Z. Xia, Study on seismic behavior \& shear capacity of deep coupling beams with new reinforcement layouts (China University of Mining and Technology, Xuzhou, 2015)

22. L. Zhan, Experimental study on short-span coupling beams with bidiagonally reinforced bar and design advise (Chongqing University, Chongqing, 2007)

23. M. Saatcioglu, M. Grira, ACI Struct. J. 96 29-39 (1999) 